\title{
Intermolecular Interactions Between Serine and C60, C59Si, and C59Ge: A DFT Study
}

\section{Mohsen Doust Mohammadi}

Tehran University: University of Tehran

Hewa Y. Abdullah ( $\square$ hewayaseen@gmail.com )

Tishk International University https://orcid.org/0000-0001-5766-3858

\section{Research Article}

Keywords: Boron Nitride, C3H7NO3, Density Functional Theory, Serine, Wave function analysis

Posted Date: August 4th, 2021

DOl: https://doi.org/10.21203/rs.3.rs-770749/v1

License: (c) (i) This work is licensed under a Creative Commons Attribution 4.0 International License. Read Full License 
3

\title{
Intermolecular Interactions between Serine and $\mathrm{C}_{60}, \mathrm{C}_{59} \mathrm{Si}$, and C59Ge: A DFT Study
}

\author{
Mohsen Doust Mohammadia ${ }^{\text {, Hewa Y. Abdullah }}{ }^{\mathrm{b}, *}$ \\ ${ }^{a}$ School of Chemistry, College of Science, University of Tehran, Tehran 14176, Iran \\ ${ }^{b}$ Physics Education Department, Faculty of Education, Tishk International University, Erbil, 44001, Iraq \\ *corresponding author Email: hewayaseen@ gmail.com
}

\begin{abstract}
The study of intermolecular interactions is of great importance. This study attempted to quantitatively examine the interactions between Serine $\left(\mathrm{C}_{3} \mathrm{H}_{7} \mathrm{NO}_{3}\right)$ and fullerene nanocages, $\mathrm{C}_{60}$, in vacuum. As the frequent introduction of elements as impurities into the structure of nanomaterials can increase the intensity of intermolecular interactions, nanocages doped with silicon and germanium have also been studied as adsorbents, $\mathrm{C}_{59} \mathrm{Si}$ and $\mathrm{C}_{59} \mathrm{Ge}$. Quantum mechanical studies of such systems are possible in the density functional theory (DFT) framework. For this purpose, various functionals, such as B3LYP-D3, wB97XD, and M062X, have been used. One of the most suitable basis functionals for the systems studied in this research is 6-311G $(\mathrm{d})$, which has been used in both optimization calculations and calculations related to wave function analyses. The main part of this work is the study of various analyses that reveal the nature of the intermolecular interactions between the two components introduced above. The results of conceptual DFT, natural bond orbital, non-covalent interactions, and quantum theory of atoms in molecules were consistent and in favor of physical adsorption in all systems. Germanium had more adsorption energy than other dopants. The HOMO-LUMO energy gaps were as follows: $\mathrm{C}_{60}: 5.996, \mathrm{C}_{59} \mathrm{Si}: 5.309$, and C59Ge: $5.188 \mathrm{eV}$ at B3LYP-D3/6$311 \mathrm{G}$ (d) model chemistry. The sensitivity of the adsorption increased when an amino acid molecule interacted with doped $\mathrm{C}_{60}$, and this capability could be used to design nanocarrier to detect Serine amino acid.
\end{abstract}

Keyword: Boron Nitride; $\mathrm{C}_{3} \mathrm{H}_{7} \mathrm{NO}_{3}$; Density Functional Theory; Serine; Wave function analysis. 


\section{Introduction}

The first attempts to come up with the concept of intermolecular interactions were made by

41 Clausius [1], van der Waals [2], and London [3,4]. Intermolecular interactions can be divided

42 into long-range and short-range classes. The long-range class includes electrostatic, induction,

43 and dispersion forces, and it varies with the inverse powers of the distance $r^{-n}$, which is the

44 reciprocal of the intermolecular distance. Conversely, the short-range class includes exchange

45 and repulsion forces that decrease exponentially with distance, as in $e^{-\alpha r}$. Both repulsive and

46 attractive electrostatic forces arise from classical Coulombic interactions between the charge

47 distributions of two molecules. These forces are also pairwise additive and anisotropic. The

48 interacting molecules cause instantaneous fluctuations in the electron distribution, and such a

49 disruption creates dispersion forces that are pairwise additive and always attractive. Induction

50 forces, which are non-additive and attractive, are created by the distortion of the distribution of

51 molecular charges resulting from the influence of the electric fields of other molecules. Exchange

52 and repulsion are both non-additive and of opposite signs [5].

$\mathrm{Ab}$ initio calculations are a reliable method for obtaining polarizabilities (i.e., a set of

54 constants to show the charge redistribution when a molecule is exposed to an electric field) and

55 electric multipole moments used to explain the long-range forces [6]. In the case of short-range

56 forces, the theory is rather more complicated [7] due to the overlap of electron densities between

57 molecules. The previous long-range theory should be modified in terms of short-range

58 penetration [8-10], charge transfer [11], and damping effects [12-14]. Generally, full quantum

59 methods can only be well implemented in small systems, but there are technical problems with

60 large molecules [15]. The development of wave function analysis methods has helped predict the

61 nature of intermolecular interactions, even in the case of large systems. Although the ab initio 
62 methods are few, neat, and classifiable, there are countless wave function analysis methods that

63 have not yet been systematically categorized in the scientific literature.

After Feynman's famous “There's Plenty of Room at the Bottom” speech in 1959 in Caltech,

65 the history of nanoscience has seen a dramatic expansion. Early works on carbon-based nanomaterials by Iijima [16,17] and Novoselov [18-21] paved the way for the development of

67 nanotechnology in the use of inorganic nanomaterials. Among these, the structures of boron nitride are of special importance due to their extraordinary physical and chemical properties [2224]. Studies on the optoelectrical, mechanical, and thermal properties [25] of such structures are 70 still under consideration [26,27]. Furthermore, these nanomaterials are widely used, for example, 71 as nanocarrier [28-39] or nanocarriers of drugs [40-42]. These processes occur through 72 adsorption (adhesion of a particle to a surface), and they are primarily related to the 73 intermolecular interactions between the adsorbent and the adsorbate.

74 This study examined the adsorption of Serine amino acid molecule onto the surface of 75 pristine, silicon-, and germanium-doped fullerene nanocages, $\mathrm{C}_{60}, \mathrm{C}_{59} \mathrm{Si}$, and $\mathrm{C}_{59} \mathrm{Ge}$, 76 respectively. All structures, such as isolated species and complex systems, were optimized using 77 various functionals, including B3LYP-D3, wB97XD, M062X, and 6-311G(d) basis set. The most 78 stable structure in terms of electronic energy was chosen for further wave function analyses 79 using the B3LYP-D3/6-311G(d) model chemistry. We referred to the conceptual density 80 functional theory (DFT), natural bond orbital (NBO), non-covalent interactions (NCI), and 81 quantum theory of atoms in molecules (QTAIM) from among the most important and reliable 82 wave function analyses ever developed. In this study, they were used to understand the nature of 83 intermolecular interactions. All studies were performed in vacuum; therefore, the sensitivity and 84 reactivity of the adsorbent were appreciated. The main ideas of each analysis were explained in 
85 the shortest possible way, as these materials are scattered in the available resources, and it is a 86 little difficult for beginners to have them together.

87

\section{Computational details}

The Kohn-Sham DFT framework was implemented in this study. Each structure, including amino acidand nanocages, was geometrically optimized in a vacuum using the so-called Berny geometry optimization algorithm developed by H. B. Schlegel in 1982 [43]. The PBE0 functional $[44,45]$, which is the hybrid-exchange correlation form of the Perdew-BurkeErnzerhof generalized gradient approximation (GGA) [46], meta-hybrid GGA functional M062X developed by the Truhlar group [47,48], the Head-Gordon group functional $\omega$ B97XD [49], which includes dispersion and long-range corrections, and the Becke 3-parameter Lee-YangParr functional with Grimme dispersion correction B3LYP-D3 [50-52] were employed. The MC311 or 6-311G (split-valence triple-zeta) basis set in the Gaussian package [53] has been developed by many individuals [54-62]. In the current work, the 6-311(d) basis set was used (i.e., d-type Cartesian-Gaussian polarization functions). Split-valence basis sets allow orbitals to alter the size but not the shape. When polarized functions are added to the basis sets, this limitation is removed by including orbitals with an angular momentum greater than what is needed for the ground state to depict each atom. This basis set is large enough and well able to simulate molecular orbitals. Data from benchmark studies also confirm this fact [63-67]. GaussView 6.0.16 [68] and ChemCraft [69] packages were used for building molecules. Linux-based Gaussian 16 software Rev. C.01 [53] was used for self-consistent field (SCF) calculations (as link 502). The default convergence criteria remained intact during the calculations. The SCF convergence was considered by comparing the maximum force and maximum displacement with the threshold values (0.00045 Hartree/Bohr and 0.0018 Bohr). Moreover, no symmetry 
limitations were imposed on the optimization process. Wave function stability, frequency checks, and zero-point energy corrections (ZPECs) were considered to ensure the accuracy of the calculations. Stability calculations guarantee that this optimized electronic wave function may be minimal in the wave function space rather than a saddle point and that it is completely different from finding minima or saddle points on a nuclear potential energy surface. As the Gaussian software includes the NBO version 3.1 software [70-72] (as link 607), it is used to perform population analysis studies. The Multiwfn [73] package developed by Tian Lu is fed by formatted Gaussian checkpoint files for various wave function analyses. In this work, Multiwfn was used for NBO, NCI, and QTAIM studies. O'Boyle et al. developed the cclib and GaussSum [74] package to obtain the DOS diagrams.

To calculate the adsorption energy $\left(E_{\text {ads }}\right)$ of the two molecules (nanocage and SERINE), the following underlying relation is applied:

$$
E_{\text {ads }}=E_{\text {cage/amino }}-E_{\text {cage }}-E_{\text {amino }}+\Delta E_{(B S S E)}+\Delta E_{(Z P E)}
$$

where $E_{\text {cage/amino }}$ is the energy of the cluster, and $E_{\text {amino }}$ and $E_{\text {cage }}$ are the energies of the isolated amino acidand nanocage, respectively. The negative values of $E_{\text {ads }}$ (i.e., exothermic adsorptions) show that the formed amino acid/nanocage cluster is stable. The electron density of each nucleus can be determined using a function centred on another nucleus. Therefore, in all structures, the quality of the basis set is not the same. This means that the basis set of one molecule can be effective in compensating for the violation of the basis set of another molecule. This effect is called the basis set superposition error (BSSE). There are two well-known methods for the BSSE correction, (1) chemical Hamiltonian approach (CHA) [75] and Boys and Bernardi's counterpoise $(\mathrm{CP})$ correction procedure $[76,77,15]$ which $\mathrm{CP}$ method is employed in this work:

$$
\Delta E_{(B S S E)}=\Delta E_{\text {cluster }}-\Delta E_{\text {cage }}^{\text {cluster }}-\Delta E_{\text {amino }}^{\text {cluster }}
$$


132

133

134

135

136

137

\section{6}

47

The ZPECs are calculated using Eq. 3:

$$
\Delta E_{(Z P E)}=\Delta E_{\text {cluster }(Z P E)}-\Delta E_{\text {cage }(Z P E)}-\Delta E_{\text {amino }(Z P E)}
$$

\section{Result and discussion}

\subsection{Methodology}

The DFT concept was initiated by Thomas [78], Fermi [79], and Dirac [80] in 1927-1930 using uniform electron amino acidenergy densities. In 1951, Slater [81] opened a new horizon, which Hohenberg, Kohn, and Sham [82,83] turned into a complete theory in 1964-1965. In DFT, the overall energy is shown in terms of the full electron density instead of the complicated $N$ electron wave function. DFT is considered an exact theory (not a model like the Hartree-Fock model), but the approximations that are applied have caused it to fail; nevertheless, it is an efficient and usable tool [84]. The Hartree-Fock model and Kohn-Sham DFT are presented as follows [85,84]:

$$
\begin{gathered}
E_{H F}=V+\langle h \rho\rangle+1 / 2\langle\rho J(\rho)\rangle-1 / 2\langle\rho K(\rho)\rangle \\
E_{K S}=V+\langle h \rho\rangle+1 / 2\langle\rho J(\rho)\rangle+\underset{X_{4}}{E_{4}\left[\rho_{2}\right]+\underset{4}{E_{C C}}[\rho]}[\rho]
\end{gathered}
$$

where $V$ is the nuclear repulsion energy, $\rho$ is the density matrix, $\langle h \rho\rangle$ is the one-electron (kinetic plus potential) energy, $1 / 2\langle\rho J(\rho)\rangle$ is the classical electron repulsion, $-1 / 2\langle\rho K(\rho)\rangle$ is the exchange energy, $E_{\mathrm{X}}[\rho]$ is the exchange functional, and $E_{\mathrm{C}}[\rho]$ is the correlation functional. By comparing relations 4 and 5, in Kohn-Sham formalism, the Hartree-Fock model is essentially a special case of DFT, where $E_{\mathrm{X}}[\rho]=-1 / 2<\rho K(\rho)>$ and $E_{\mathrm{C}}[\rho]=0$. Accordingly, in DFT, the methods differ in having different functionals $E_{\mathrm{X}}$ and $E_{\mathrm{C}}$. 
Unfortunately, exact functionals for exchange and correlation are not known; therefore, approximations have historically been developed to approach the real values of physical quantities, such as local-density approximation (LDA), generalized gradient approximations (GGA) [86,46], meta-GGA, and hyper-GGA. In this respect, a number of functionals include only the exchange part, such as Becke 88 (B88) [86] and Gill96 (G96) [87], and some of them include a pure correlation part, such as Vosko-Wilk-Nusair (VWN5) [88], Perdew 86 (P86) [89], Lee-Yang-Parr (LYP) [90], Perdew-Zunger (PZ81) [91], Cole-Perdew (CP) [92], and PerdewWang (PW92) [93]. Conversely, Becke 97 (B97) [94], Perdew-Burke-Ernzerhof (PBEPBE) [44], and Perdew-Wang 91 (PW91PW91) [95] are examples of exchange-correlation functionals (see Head-Gordon et al. article for a general overview of the types of functionals to a climb of Jacob's ladder [64]). The origine of the diferences among the $E_{\mathrm{XC}}[\rho]$ arise from exchangecorrelation holes (i.e. an exclusion area around electron or a "no-fly zone" which prevents other electron to penetrate, each functional has its own XC fingerprint).

In the present study, the hybrid functionals PBE0 and B3LYP-D3 were used. Note that the D3 in B3LYP-D3 refers to the D3 version of Grimme's dispersion with Becke-Johnson damping (GD3BJ) [52]. In hybrid functions, the exchange energy is divided into two parts to improve performance. The first part is the result of accurate calculations obtained from Hartree-Fock calculations, and the next part of the exchange energy is calculated using the DFT method. B3LYP uses three mixing parameters:

$$
\begin{aligned}
& E_{\mathrm{XC}}=\mathrm{A}^{*} E_{\mathrm{X}}(\mathrm{LSDA})+(1-\mathrm{A}) * \mathrm{E}_{\mathrm{X}}(\mathrm{HF})+\mathrm{B} * \Delta E_{\mathrm{X}}(\mathrm{B} 88) \\
& +E_{\mathrm{C}}(\mathrm{VWN})+\mathrm{C}^{*} E_{\mathrm{C}}(\mathrm{LYP})
\end{aligned}
$$

and PBE0 consists of a 1:3 mixture of Hartree-Fock (HF) and DFT exchange energies:

$$
E_{\mathrm{XC}}=0.25 * E_{\mathrm{X}}(\mathrm{HF})+0.75 * E_{\mathrm{X}}(\mathrm{PBE})+E_{\mathrm{C}}(\mathrm{PW} 91)
$$


B3LYP has a weakness in considering charge transfer excitations, as it is not a long-range corrected functional [96]. This means that it uses a constant of $20 \%$ HF exchange for both short and long ranges. CAM-B3LYP [97] and $\omega$ B97XD are range-separated hybrid functionals [98] that are suitable for excitation energy calculations and conjugated systems [99]. $\omega \mathrm{B} 97 \mathrm{XD}$ is a range-separated version of the B97 functional with Grimme's D2 dispersion model (addition of an empirical $\mathrm{C}_{6} \cdot \mathrm{R}^{-6}$ dispersion term). In short-range interactions, it comprises $22 \% \mathrm{HF}$ exchange contributions and $100 \% \mathrm{HF}$ in the long-range. A standard error function is implemented to describe the intermediate region using a range separation parameter (i.e., $\omega=0.2-0.3$ Bohr $^{-1}$ ) [100]. The range-separated term consists of two parts which splits the DFT exchange interaction as follows:

$$
\frac{1}{r_{12}}=\frac{\alpha+\beta * \operatorname{erfc}\left(\omega r_{12}\right)}{r_{12}}+\frac{\alpha+\beta * \operatorname{erf}\left(\omega r_{12}\right)}{r_{12}} \quad ; \quad \operatorname{erfc} \equiv 1-\operatorname{erf}
$$

The first term in Eq. 8 shows short-range contribution which is singular and decays to zero on a length scale of $\sim 1 / \omega$ and the second term is related to non-singular long-range part. The $a$ and $\beta$ parameters allow HF-exchange and DFT exchange incorporate over whole range. M06-2X, a meta-hybrid GGA functional with double non-local exchange (2X) amounts, belongs to the M06 suite of functionals with 54\% HF contributions, in which the non-interacting kinetic energy density is used as input to the functional and the electron density and its gradient [101]. This functional is well defined for systems with dispersion forces.

\subsection{Geometric surveys}

In the first step, molecular geometries were constructed using GussView software. The method of making nanocages is explained fully in the Help section of the software. Creating a Serine amino acid molecule does not take much effort, but for more certainty, geometry related 
201 to amino acidmolecules was prepared using the PubChem online database [102]. At the 202 beginning of the research, we chose models that were faster and less expensive. All structures, 203 including isolated molecules and clusters, were initially examined using PBE0/6-311G(d) model. 204 As our ultimate goal was to examine intermolecular forces, we used models that calculated 205 intermolecular interactions more accurately. The optimization process was repeated with the 206 same basis set and functionals M06-2X, B3LYP-D3, and $\omega$ B97XD. The chemistry of the 207 different models varied within the trade-offs made between computational cost and accuracy.

208 Once geometric optimization was completed, the presence or absence of imaginary 209 frequencies (i.e., frequencies that have negative values do not represent the minimum and 210 actually represent a transition state) was examined. Thus, in each optimized structure, frequency 211 calculations were performed. In the output file of the Gaussian software, the keyword Nimag was 212 assigned for this purpose. A value of zero (Nimag $=0$ ) means that there are no negative 213 frequencies according to the number of negative eigenvalues of the Hessian matrix. Frequency 214 calculations were performed to determine the ZPEC, which must be added to the total energy.

215 To study the interactions between nanocages and a amino acid molecule, a $\mathrm{C}_{60}$ cage with $2161.45 \AA$ bond length was selected. The optimized C60 structure was used to prepare a doped 217 nanocage. For this purpose, doped nanocages were obtained by substituting silicon and 218 germanium instead of carbon atom and they were re-optimized in the same optimization process.

219 Each nanocage is illustrated in Fig. 1, which shows the position of the doped elements 220 compared with the pure nanocage. The injection of the doped elements slightly changed the 221 length of the bonds, indicating that the electronic structure was altered. These changes in the 222 electronic structure led to differences in properties. Doping is a critical and successful strategy 223 for detecting the properties of a nanomaterial as an adsorbent [103]. The dopants alter the 
224 sensing properties by changing the HOMO-LUMO gap and morphology, creating more centres

225 for amino acidinteraction on the adsorbent surface.

As shown in Fig. 2, there are five sites on the nanocage that have the potential to absorb the

227 amino acidmolecule. The top of the carbon atom is represented by $T_{1}$. The position of $T_{2}$ is

228 related to the placement of the amino acidmolecule on top of the bond beween two hexagonal

229 rings . The $T_{3}$ position is the placement of the amino acidmolecule on top of the bond beween

230 hexagonal and pentagonal rings. The $T_{4}$ position is located above the hexagonal ring. And $T_{5}$ is

231 on top of the pentagonal ring. Structurally, the Serine molecule has four heads, each of which

232 can be placed on any of the five adsorption sites in C60 (Fig. 3).

233 The starting point of the study is placing the amino acid molecule on the absorbent surface

234 in different positions with different angles and distances and with different orientations and

235 optimizing the whole cluster system. Finding the global minimum is the most challenging step of

236 the study. Although we may never get it right away in the computing process, various strategies

237 can be used to find many local minima and choose the most stable mode based on their

238 quantitative value. If we have the full potential energy surface (PES) of two fragments, we can

239 easily report the global minimum. However, having the PES requires thousands of calculations,

240 which are practically impossible. The approach followed in this research is based on placing the

241 amino acidmolecule on the adsorbent surface at different distances and orientations. For this

242 purpose, a low-cost method, such as PM6, was used. Dozens of initial orientations were selected

243 to achieve the most stable structure in terms of energy content. The PEB0/6-311G(d) model

244 chemistry was used to optimize the obtained stable structure and repeat the process using the 245 abovementioned functionals. 


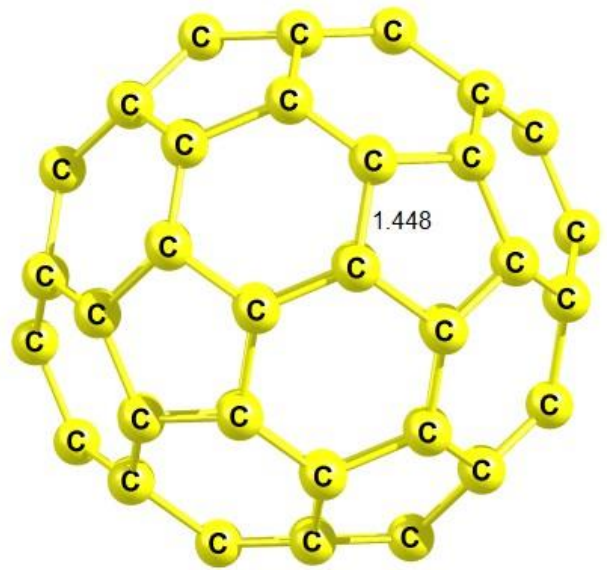

(a)

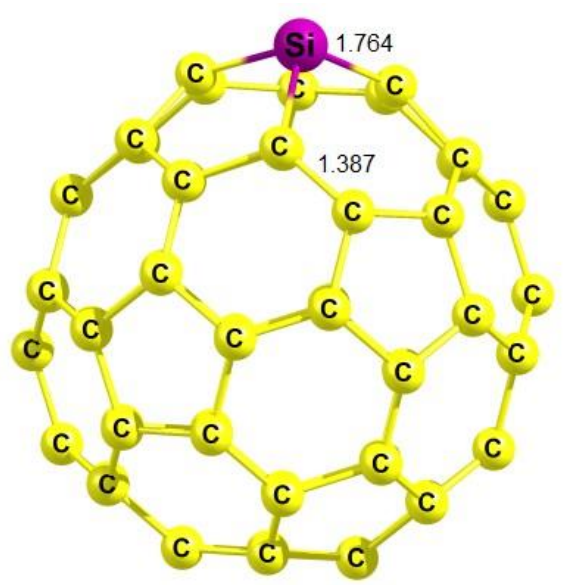

(b)

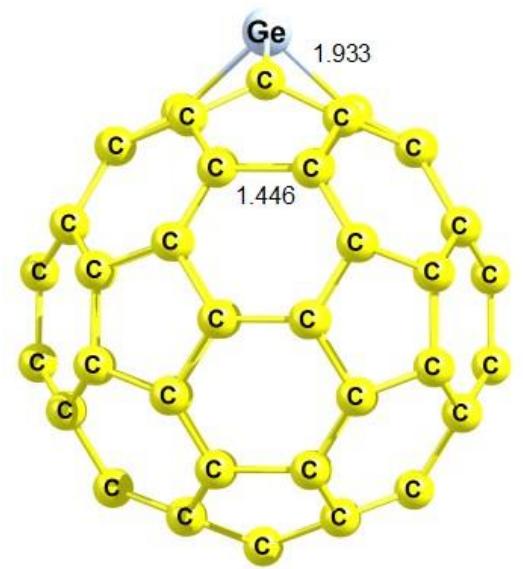

(c)

Fig. 1. The values of bond length for (a) $\mathrm{C}_{60}$, (b) $\mathrm{C}_{59} \mathrm{Si}$, and (c) $\mathrm{C}_{59} \mathrm{Ge}$. The optimization process has been done using the B3LYP-D3/6-311G (d) level of theory. 
The relaxed cluster structures obtained from B3LYP-D3/6-311G (d) are illustrated in Fig.

252 4. When the value of the energy of adsorption is below the range of chemical interest (i.e., from

253 the third decimal place onwards following the decimal point), the results are identical [104].

254 Table 1 lists the values obtained from the calculations of the four different methods for

255 optimizing complex structures. The quantitative amounts of adsorption energies obtained from

256 the 6 B97XD and B3LYP-D3 models were similar. Moreover, PBE0 data showed how different

257 the data would be if the dispersion effect was not considered. Among the four different models,

258 the values obtained from the B3LYP-D3/6-311G (d) model showed the highest stability, based

259 on the absolute value of the highest absorption energy. As indicated in Table 1, among the doped

260 elements, germanium produced the highest absorption energy $(-1.975 \mathrm{eV})$.

261 To understand the nature of intermolecular forces, whether they are strong or weak or are

262 the result of van der Waals or electrostatic effects, the wave function is analyzed in the following

263 sections. According to Table 1 and based on our previous experience $[105,106]$, the B3LYP-D3

264 functional is a better match to the systems studied in this paper. Thus, it was used for the wave

265 function analysis calculations.

266 Table1

267 The interaction energy $\left(E_{\text {ads }}\right)$ for $\mathrm{C}_{60}, \mathrm{C}_{59} \mathrm{Si}$, and $\mathrm{C}_{59} \mathrm{Ge}$ with Serine molecule. All values are in (eV).

\begin{tabular}{|c|c|c|c|c|}
\hline Systems & PBE0 & B3LYP-D3 & M06-2X & $\omega B 97 X D$ \\
\hline Serine/C $\mathrm{C}_{60}$ & -0.824 & -1.342 & -1.108 & -1.231 \\
\hline Serine/C $\mathrm{C}_{59} \mathrm{Si}$ & -1.113 & -1.600 & -1.760 & -1.658 \\
\hline Serine/ $\mathrm{C}_{59} \mathbf{G e}$ & -1.289 & -1.788 & -1.975 & -1.843 \\
\hline
\end{tabular}




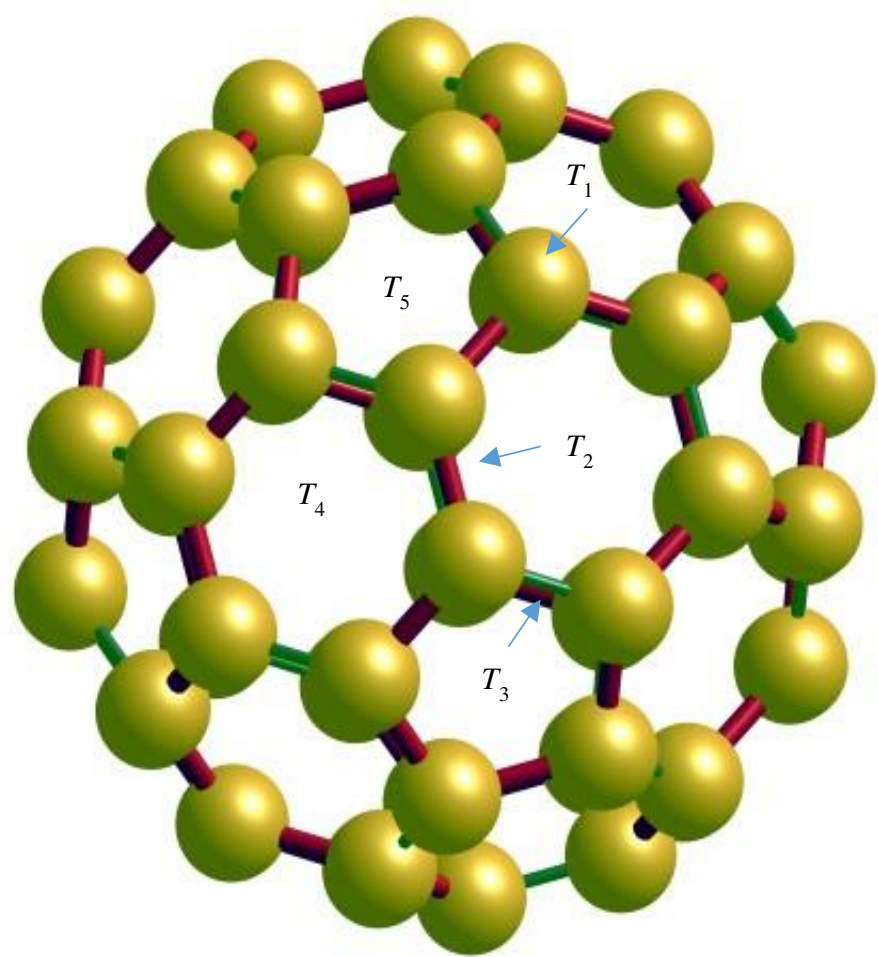

272 Fig. 2. The $(T x)$ positions including on top of carbon atom $\left(T_{1}\right)$, on top of the bond beween two hexagonal rings $\left(T_{2}\right)$, on top of the bond beween hexagonal and pentagonal rings $\left(T_{3}\right)$, on top of the hexagonal ring $\left(T_{4}\right)$, and top of 274 the pentagonal ring $\left(T_{5}\right)$.

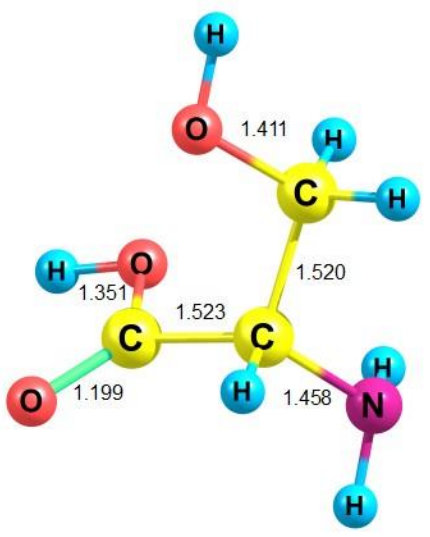

Fig. 3. The values of bond length for Serine molecule. The optimization process has been done using the B3LYP- 


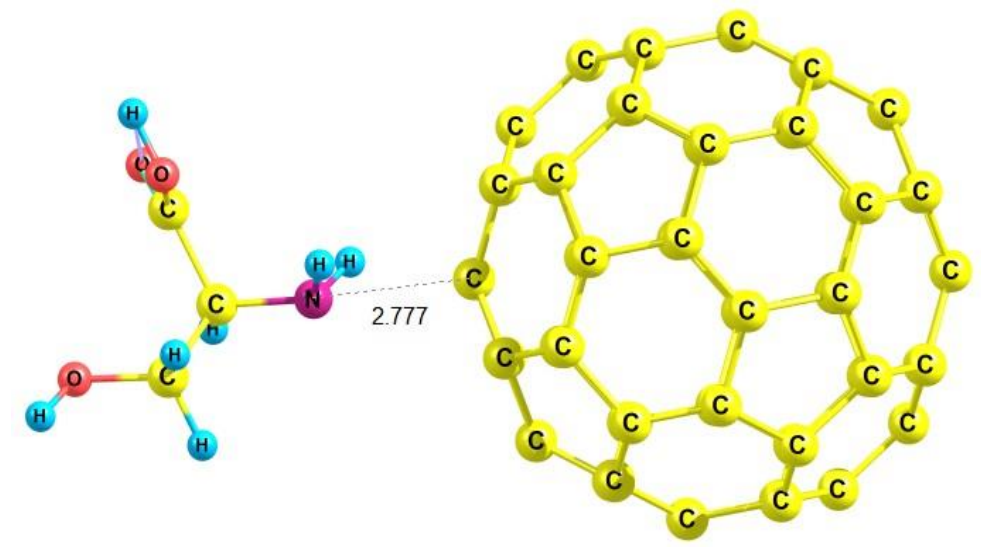

(a)

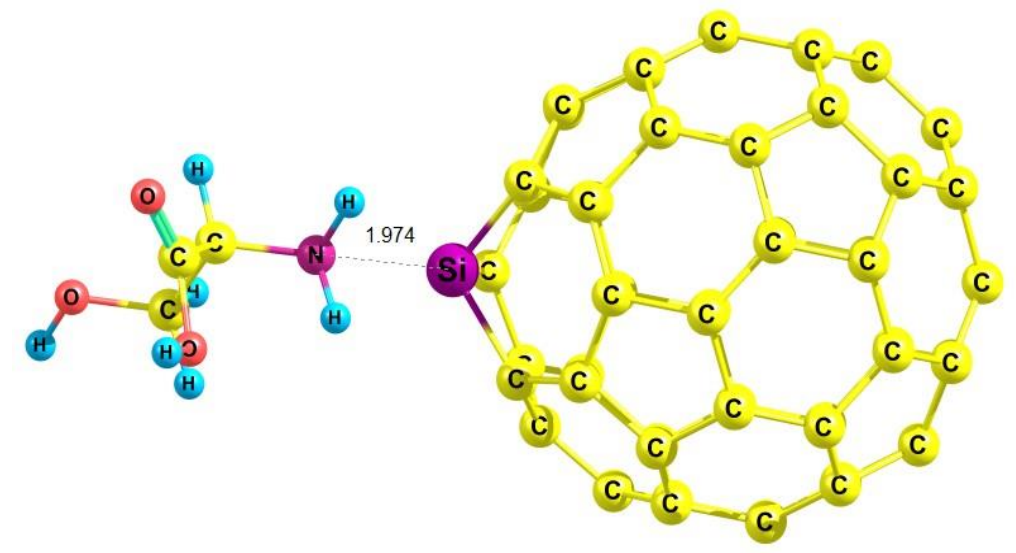

(b)

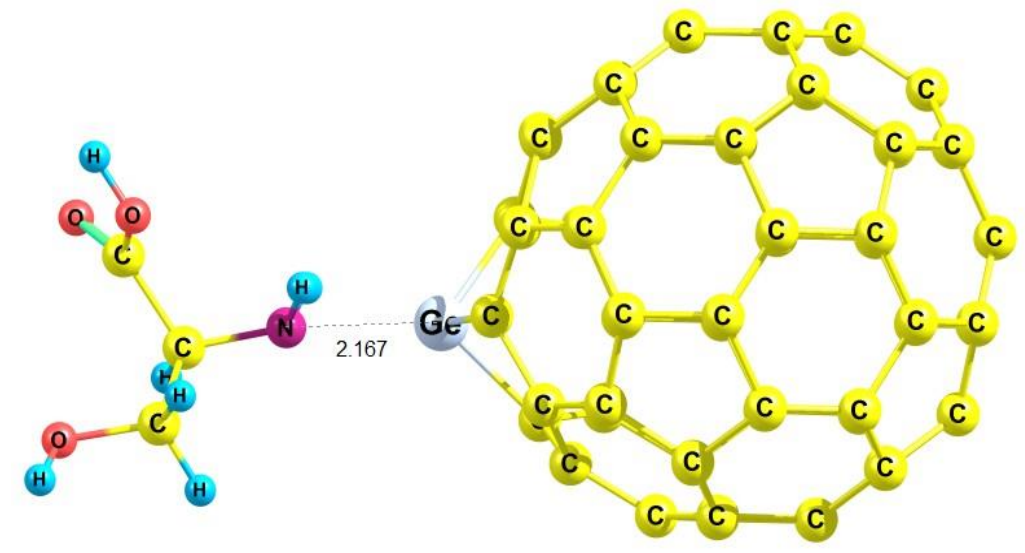

(c)

282 Fig. 4. The most stable form of (a) Serine/ $\mathrm{C}_{60}$, (b) Serine $/ \mathrm{C}_{59} \mathrm{Si}$, and (c) Serine $/ \mathrm{C}_{59} \mathrm{Ge}$. All clusters have been optimized using the B3LYP-D3 functional and 6-311G(d) basis set. 


\subsection{Conceptual DFT descriptors}

The conceptual DFT descriptors, including chemical potential $(\mu)$, chemical hardness $(\eta)$, electronegativity $(\chi)$, electrophilicity $(\omega)$, and nucleophilicity $(1 / \omega)$, are implemented to consider the chemical reactivity/stability of certain atomic sites of molecules, the charge transfer through nucleophilic or electrophilic attacks, and the analysis of chemical reactions [107-109]. According to the basic principles of DFT, energy is a functional of the wave function (a functional can be used to turn a function into a number [110]), and the changes in the number of particles, $\Delta N$, and external potential, $\Delta v(\mathbf{r})$, can describe a typical process. Therefore, if we have the ground state energy, $E[N, v(\mathbf{r})]$, of an $N$ electron system, the energy of the perturbed system can be obtained as follows [111]:

$$
\begin{aligned}
\Delta E & \equiv E[N+\Delta N, v(\mathbf{r})+\Delta v(\mathbf{r})]-E[N, v(\mathbf{r})] \\
& =\left(\frac{\partial E}{\partial N}\right)_{v} \Delta N+\int\left(\frac{\delta E}{\delta v(\mathbf{r})}\right)_{N} \delta v(\mathbf{r}) d(\mathbf{r})+ \\
& \frac{1}{2 !}\left\{\left(\frac{\partial^{2} E}{\partial N^{2}}\right)_{v} \Delta N^{2}+2 \int\left(\frac{\partial}{\partial N}\left(\frac{\delta E}{\partial v(\mathbf{r})}\right)_{N}\right)_{v} \Delta N \delta v(\mathbf{r})+\iint\left(\frac{\partial^{2} E}{\partial v^{2}(\mathbf{r})}\right)_{N} \delta v(\mathbf{r}) \delta v\left(\mathbf{r}^{\prime}\right) d \mathbf{r} d \mathbf{r}^{\prime}\right\}+\ldots
\end{aligned}
$$

The above Taylor expansion is usually truncated in the second order. The coefficients of the expansion have specific meanings in chemical language. For example, for non-degenerate states, perturbation theory describes electron density, $\rho(\mathbf{r})$, as follows $[112,113]$ :

$$
\left(\frac{\delta E}{\delta v(\mathbf{r})}\right)_{N}=\rho(\mathbf{r})
$$

Parr et al. [114] proved that $\mu$ is a quantitative measure of the tendency of an electron to pull out a system. The direction is from high to low $\mu$ values. The electronic chemical potential $(\mu)$ and electronegativity $(\chi)$ relation are expressed as Eq. 10

$$
-\chi=\left(\frac{\partial E}{\partial N}\right)_{v(r)}=\mu \cong \frac{\left(\varepsilon_{L U M O}+\varepsilon_{H O M O}\right)}{2}=\frac{1}{2}(I P+E A)
$$

Pearson [115] showed hardness $(\eta)$ as a measure of resistance of a system to a change in the electronic cloud as follows: 


$$
\eta=\left(\frac{\partial \mu}{\partial N}\right)=\frac{1}{2}\left(\frac{\partial^{2} E}{\partial N^{2}}\right)_{v(r)}=\frac{1}{2}(I P-E A)
$$

Similarly, the Fukui function (which shows the change of $\rho(\mathbf{r})$ at a given position by changing of

311 follows:

$$
f(r)=\left(\frac{\delta^{2} E}{\delta v(r) \partial N}\right)=\left(\frac{\partial \rho(r)}{\partial N}\right)_{v(r)}=\left(\frac{\partial \mu}{\delta v(r)}\right)_{N}
$$

$$
\Delta f(r)=\left(\frac{\delta^{3} E}{\delta v(r) \partial^{2} N}\right)=\left(\frac{\partial f(r)}{\partial N}\right)_{v(r)}=\left(\frac{\partial \eta}{\delta v(r)}\right)_{N}
$$

Electrophilicity $(\omega)$ [119] is not the coefficient of the above-mentioned expansion. At the

to accept an arbitrary number of electrons). In addition, a maximum number of electrons gained by the system $\Delta N_{\max }$ [120] prove that a typical system can be stabilized by gaining electrons when $\mu<0$ and $\eta>0$. Electrophilicity $(\omega)$ and $\Delta N_{\max }$ are defined as

$$
\omega=\frac{\mu^{2}}{2 \eta} \approx \frac{(I P+E A)^{2}}{4(I P-E A)}
$$

$$
\Delta N_{\max }=-\frac{\mu}{\eta}
$$

322 ionization potential $(I P)$ and electron affinity $(E A)$. Theoretically, based on the Koopmans' [122]

323 and Janak's [123] approximations, the ionization potential is equal to the negative value of

$324 \mathrm{HOMO},\left(\varepsilon_{\text {HОмO }}=-I P\right)$, and the electron affinity is equal to the negative value of LUMO,

$325\left(\varepsilon_{L U M O}=-E A\right)$. It should be noted that HOMO and LUMO can only be obtained from HF or 326 DFT (i.e single determinant methods) and the LUMO has no contribution to the total energy of 
327 the system. In addition, calculating the LUMO values is basis set sensitive; however, methods

328 have been developed that can eliminate the LUMO dependence on the basis set [124].

The values of these descriptors are presented in Table 2 . The energy gap $\left(E_{\mathrm{g}}\right)$ of C60 was $5.996 \mathrm{eV}$ using the B3LYP-D3/6-311G (d) model chemistry, and the adsorption of Serine on it

331 reduced the energy gap to $5.855 \mathrm{eV}$. The silicon- and germanium-doped nanocages also reduced

332 the HLG values. Molecules with large HLG had high values of $\eta$, whereas those with low HLG

333 had low $\eta$. Table 2 shows that the LUMO values became more negative after the adsorption of

334 Serine onto the nanocages; therefore, HLG was reduced. Reactivity of species was obvious due

335 to the values of the descriptors $\eta$ and $\mu$. Conductivity arose from a high level of reactivity, and

336 the charge transfer between the cages and adsorbate could be implemented through an chemical

337 device as a carrier. To obtain a visual image of how the energy levels, especially HOMO and

338 LUMO, are positioned, the total density of state maps is used in Fig. 5.

\section{Table 2}

HOMO energy $\left(\varepsilon_{\mathrm{H}}\right)$, LUMO energy $\left(\varepsilon_{\mathrm{L}}\right)$, HOMO-LUMO energy gap (HLG), chemical potential $(\mu)$, chemical hardness $(\eta)$, and electrophilicity $(\omega)$. All values are in eV and were obtained using the B3LYP-D3/6-311G (d) level of theory.

\begin{tabular}{|c|c|c|c|c|c|c|}
\hline Systems & $\boldsymbol{\varepsilon}_{\mathrm{H}}$ & $\boldsymbol{\varepsilon} \mathbf{L}$ & HLG & $\mu$ & $\eta$ & $\omega$ \\
\hline $\mathrm{C}_{60}$ & -8.176 & -2.179 & 5.996 & -5.177 & 2.998 & 40.183 \\
\hline $\mathrm{C}_{59} \mathrm{Si}$ & -7.848 & -2.540 & 5.309 & -5.194 & 2.654 & 35.805 \\
\hline $\mathrm{C}_{59} \mathrm{Ge}$ & -7.954 & -2.766 & 5.188 & -5.360 & 2.594 & 37.266 \\
\hline Serine/ $\mathrm{C}_{60}$ & -8.043 & -2.188 & 5.855 & -5.116 & 2.928 & 38.308 \\
\hline Serine/ $\mathbf{C}_{59} \mathbf{S i}$ & -7.024 & -1.760 & 5.264 & -4.392 & 2.632 & 25.382 \\
\hline Serine $/ \mathrm{C}_{59} \mathrm{Ge}$ & -7.023 & -1.907 & 5.117 & -4.465 & 2.558 & 25.503 \\
\hline
\end{tabular}




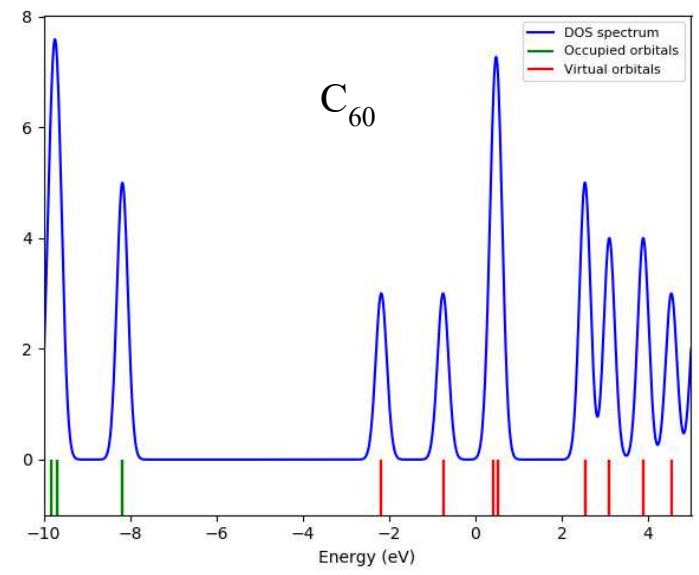

(a)
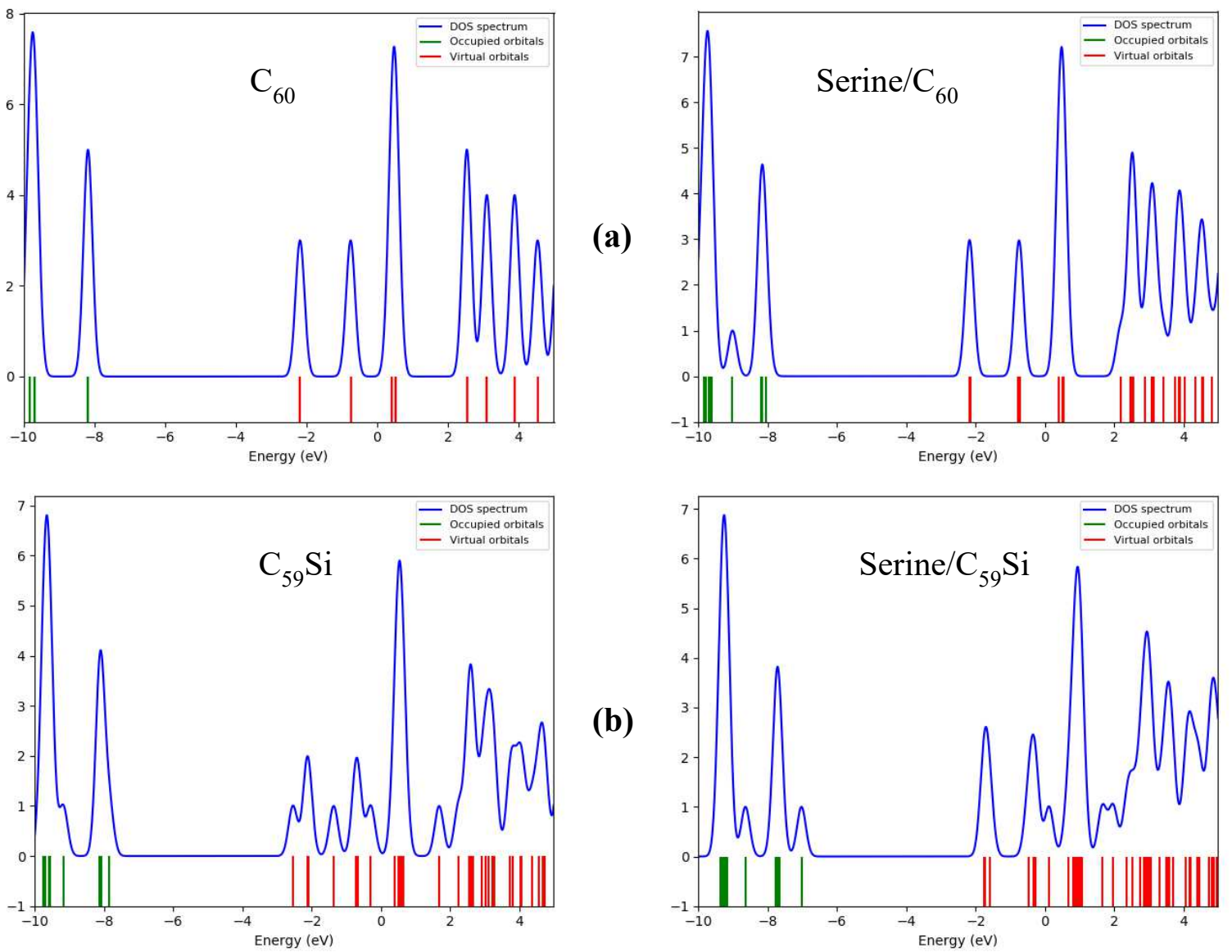

(b)
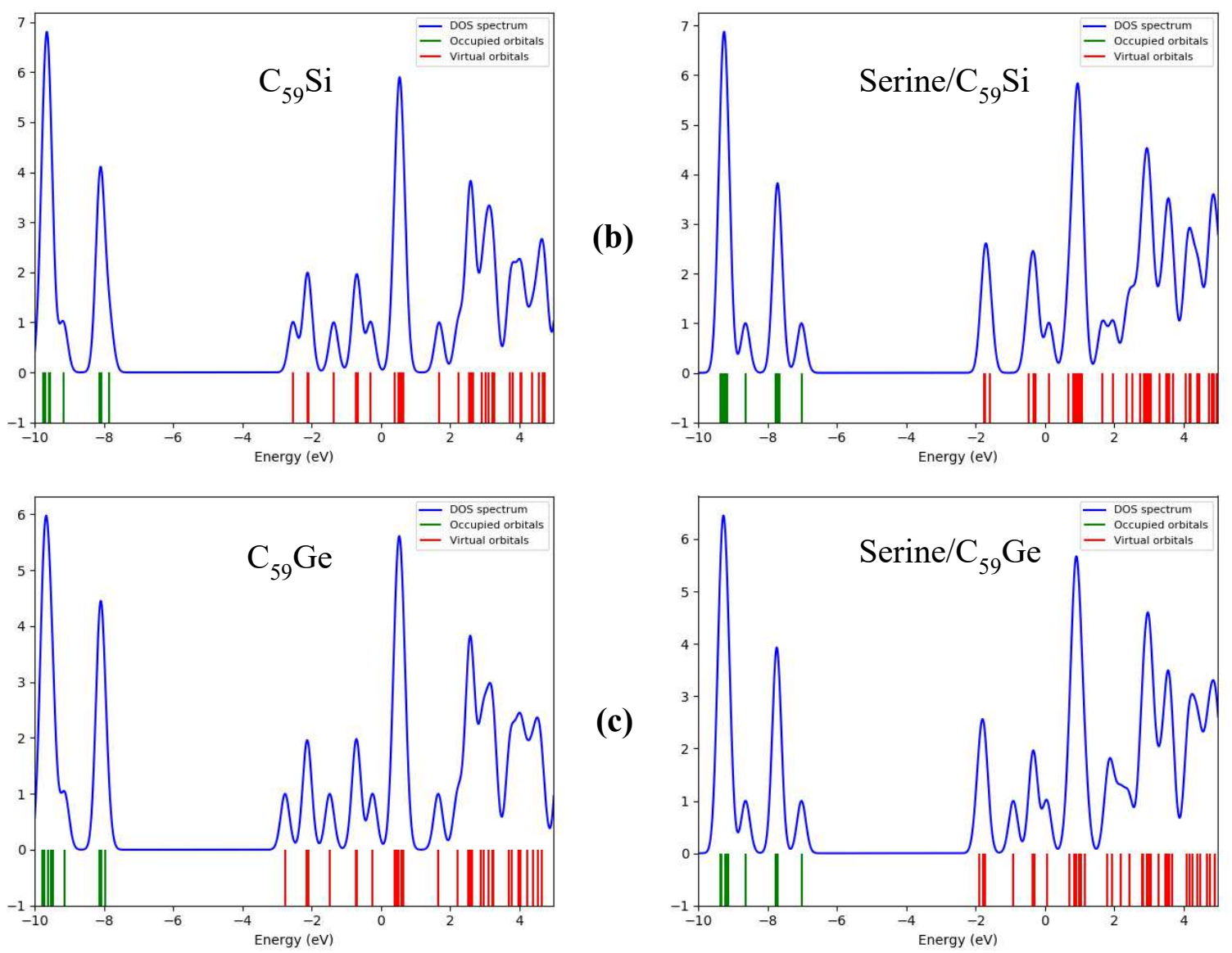

Fig. 5. Density of state maps for (a) $\mathrm{C}_{60}$ and Serine/ $\mathrm{C}_{60}$, (b) $\mathrm{C}_{59} \mathrm{Si}$ and Serine $/ \mathrm{C}_{59} \mathrm{Si}$, and (c) $\mathrm{C}_{59} \mathrm{Ge}$ and $\mathrm{Serine} / \mathrm{C}_{59} \mathrm{Ge}$. 348 Data were obtained from the B3LYP-D3/6-311G (d) model chemistry. 


\section{$3.4 N B O$ analysis}

Canonical molecular orbitals (MO) lead to delocalized descriptions of electrons derived directly from SCF methods [125]. Delocalization means that the MO obtained from several electrons belongs to adjacent atoms. As this is physically difficult to imagine, to create physical intuition, we had to use a method that would give us an understanding. As the wave function is invariant under unitary transformations, localization is possible. The NBO [70] method, developed by Weinhold et al., is an intuitive method used to reach localized and understandable orbitals (i.e., localized Lewis-like electronic structures) using the first-order reduced density matrix of the wave function.

Various types of NBO analyses offer tremendous power to display bond order, Lewis structures, donor-acceptor interactions, charge transfer, resonance weights, bond type, and hybridization. The validity of NBO analysis extends from atoms to supermolecules, spanning the entire periodic table. The term "natural" was introduced by Löwdin [126]. NBO analysis uses natural orbitals, as NBOs are obtained as local block eigenfunctions of the density matrix. "Bond orbital" means that the NBO algorithm calculates the distribution of electron density in bonds between atoms. Generally, NBO methods serve as a bridge between wave function and elementary valency and bonding concepts.

Providing a complete orthogonal set of natural atomic orbitals (NAOs), localized onecentre orbitals from the atom-centred basis set are the most fundamental parts of the NBO algorithm. To perform a natural population analysis, natural hybrid orbitals (NHOs), NBOs, and natural localized molecular orbitals (NLMOs) must be obtained from NAOs to transform a given wave function into localized orbitals that correspond to the one-centre ("lone pair") and twocentre ("bond") elements of the Lewis structure picture: 
For a $(\sigma)$ bond located between atoms A and B, the NBO is defined as follows:

where $C_{A}$ and $C_{B}$ are the corresponding polarization coefficients (for covalent bonds $C_{\mathrm{A}}=C_{\mathrm{B}}$; if the electronegative $\mathrm{A}$ is assumed to be greater than $\mathrm{B}$, we have: $\left.C_{\mathrm{A}} \gg C_{\mathrm{B}}\right)$. The $h_{A}$ and $h_{B}$ are natural hybrid valance orbitals. To complete the span of valance space, an antibonding NBO ( $\left.\sigma^{*}\right)$ is also defined as follows: of chemical bonding has paved the way for many chemical bond analyses [127]. The most popular methods used to find the bond order are the Mulliken bond order analysis [128] (Equation 19), the Mayer bond order [129-131] (Equation 20), and the Wiberg bond index (WBI)

$$
\sigma_{A B}^{*}=C_{A} h_{A}-C_{B} h_{B}
$$

In this study, NBO methods were utilized to measure the bond order. Coulson's definition in Löwdin orthogonalized basis [132,133] (Equation 21). Therefore,

where $P$ is the density matrix, and $\mathrm{S}$ is the overlap matrix. Compared with Mulliken and Mayer's 400 bond orders, WBI has less basis set dependence, especially the basis set that includes diffuse 401 functions, and it provides more accurate results. The WBI values are reported in Table 3. 402 Accordingly, we can conclude that $\mathrm{C}_{59} \mathrm{Si}$ and $\mathrm{C}_{59} \mathrm{Ge}$ adsorbents are more active materials in this 
study in adsorbing Serine compared with pristine $\mathrm{C}_{60}$. The WBI values show that the interaction

404 of the amino acidmolecule with $\mathrm{C}_{60}$ can be classified as a weak interaction. Conversely, the

405 interactions between silicon- and germanium-doped $\mathrm{C}_{60}$ with the Serine molecule are stronger

406 than the van der Waals interactions. The results of the WBI are in good agreement with the

407 adsorption energies reported in Table 1.

408 Table 3

409 The, Mayer, Mulliken, and Wiberg bond index obtained for atomic bonds and intermolecular interactions between

410 Serine molecule and $\mathrm{C}_{60}, \mathrm{C}_{59} \mathrm{Si}$, and $\mathrm{C}_{59} \mathrm{Ge}$. All calculations were performed using the B3LYP-D3/6-311G(d) level 411 of theory.

\begin{tabular}{|c|c|c|c|}
\hline Systems & Mulliken & Mayer & Wiberg \\
\hline Serine/ $\mathbf{C}_{60}$ & 0.066 & 0.099 & 0.201 \\
\hline Serine/ $\mathbf{C}_{59} \mathbf{S i}$ & 0.136 & 0.162 & 0.469 \\
\hline Serine $/ \mathrm{C}_{59} \mathbf{G e}$ & 0.188 & 0.268 & 0.582 \\
\hline
\end{tabular}

412

413

414

415

3.5 QTAIM analysis

The idea that a molecule is a collection of atoms linked by a network of bonds is not

417 directly related to quantum mechanics and is beyond theoretical definition. Bader's topological

418 quantum theory of atoms in molecules (QTAIM) analysis $[134,135]$ was developed to answer the

419 question, "What is an atom in a molecule and how does one predict its properties?" Based on the

420 topology of the electron density, the structure of a molecule is revealed by the stationary points

421 of the electron density and the gradient paths that originate and terminate at these points. In the

422 AIM method, electrons are distributed in space in the gravitational field of the nucleus. This

423 means that the nucleus exists as a point in a cloud of negative charge with an electron density

424 distribution. Electron density $\rho(\mathbf{r})$ is a measurable property that determines the shape and

425 properties of atoms and materials in general. 
In this theory, a critical point is a minimum or a maximum of electron density $(\nabla \rho(\mathbf{r})=0)$. A

427 chemical bond is defined as a line between two atoms, in which the electron density is the 428 maximum along with. There are trajectories that both originate and terminate at critical points

429

430

431

432

433

434

435

436

437

438

439

440

441

442

443 provide useful information about the different types of chemical interactions. The amount of $\rho(\mathbf{r})$

444 in BCP determines the bond strength and the bond order. In the case of the covalent bond, the

445 Laplacian is less than zero $\left(\nabla^{2} \rho(\mathbf{r})<0\right)$, and the values of $\rho(\mathbf{r})$ are large, indicating that the

446 charges are concentrated between two nuclei. The positive values of the Laplacian $\left(\nabla^{2} \rho(\mathbf{r})>0\right)$ 
447 and the low values of $\rho(\mathbf{r})$ indicate that the charge dissipates in the distance between the two 448 nuclei and that the interactions can be classified as a closed-shell type, which is related to ionic 449 bonds, hydrogen bonds, and van der Waals bonds [137]. In particular, in the case of hydrogen 450 bonding, if the electron density is in the range of $0.035-0.002$ and if the Laplacian of electron 451 density is in the range of $0.0139-0.002$, the bond can be a hydrogen type.

The values of the Lagrangian kinetic energy $G(\mathbf{r})$, potential energy density $V(\mathbf{r})$, and energy density $H(\mathbf{r})=G(\mathbf{r})+V(\mathbf{r})$ can also be helpful in identifying the type of interactions. For a covalent bond, $H(\mathbf{r})<0 ; H(\mathbf{r}) / \rho(\mathbf{r})>>0$; and $G(\mathbf{r}) /|V|(\mathbf{r})<0.5$. For non-covalent interactions, $\mathrm{H}(\mathrm{r})>0 ; \mathrm{H}(\mathrm{r}) / \rho(\mathrm{r})>0$; and $\mathrm{G}(\mathrm{r}) /|\mathrm{V}|(\mathrm{r})>1$. The virial theorem [138] suggests a relationship between $G(\mathbf{r}), V(\mathbf{r})$, and $\nabla^{2} \rho(\mathbf{r})$,

$$
\frac{1}{4} \nabla^{2} \rho(\mathbf{r})=2 G(\mathbf{r})+V(\mathbf{r})
$$

Here, $\varepsilon$ can be used to refer to the stability of the interactions and is defined as follows [139]:

$$
\varepsilon=\frac{\lambda_{1}}{\lambda_{2}}-1 ; \quad \lambda_{1}<\lambda_{2}<0 ; \text { and } \lambda_{3}>0
$$

\section{Table 4}

The AIM topological parameters, including electron density $(\rho(r))$, Laplacian of electron density $\left(\nabla^{2} \rho(\mathrm{r})\right)$, the kinetic electron density $G(\mathrm{r})$, potential electron density $V(\mathrm{r})$, eigenvalues of Hessian matrix $(\lambda)$, and bond ellipticity index (e) at BCPs of the Serine molecule and $\mathrm{C}_{60}, \mathrm{C}_{59} \mathrm{Si}$, and $\mathrm{C}_{59} \mathrm{Ge}$. All values have been calculated using the B3LYP$\mathrm{D} 3 / 6-311 \mathrm{G}(\mathrm{d})$ level of theory from NBO analysis.

\begin{tabular}{lccccccccc}
\hline Systems & $\boldsymbol{\rho}$ & $\boldsymbol{\nabla}^{2} \boldsymbol{r}$ & $\boldsymbol{G}(\mathbf{r})$ & $\boldsymbol{V}(\mathbf{r})$ & $\boldsymbol{G}(\mathbf{r}) / \boldsymbol{V}(\mathbf{r})$ & $\boldsymbol{\lambda}_{\boldsymbol{I}}$ & $\boldsymbol{\lambda}_{2}$ & $\boldsymbol{\lambda}_{3}$ & $\boldsymbol{\varepsilon}$ \\
\hline Serine/C60 & 0.0341 & 0.1339 & 0.0320 & -0.0306 & 1.0472 & -0.0107 & 0.1757 & -0.0311 & 1.8966 \\
Serine/C59Si & 0.0638 & 0.1974 & 0.0721 & -0.0948 & 0.7604 & -0.0503 & 0.3038 & -0.0562 & 0.1171 \\
Serine/C59Ge & 0.0633 & 0.1410 & 0.0532 & -0.0711 & 0.7478 & -0.0606 & 0.2582 & -0.0566 & 0.0709 \\
\hline
\end{tabular}


472 Considering the values shown in Table 4, the Laplacian electron density $\nabla^{2} \rho(\mathbf{r})$ is positive 473 for all interactions between the Serine amino acid molecule and all nanocages. Therefore, the 474 interaction between amino acidand nanocages is detected as non-covalent. Fig. 6 shows the BCP 475 position. The presence of critical points between the amino acidmolecule and the nanocages 476 emphasizes the strong interactions between the two components. Among the nanocages, $\mathrm{C}_{59} \mathrm{Si}$ 477 and $\mathrm{C}_{59} \mathrm{Ge}$ are more capable of adsorbing the amino acidmolecule, as the values of $G(\mathbf{r}) /|V|(\mathbf{r})$ for 478 both of them are between 0.5 and 1 . This means that the interaction tends to be strong in van der 479 Waals. The other descriptors, $H(\mathbf{r})$ and $H(\mathbf{r}) / \rho(\mathbf{r})$, agree with these results. The values obtained 480 from $\varepsilon$ show stable intermolecular interactions. 


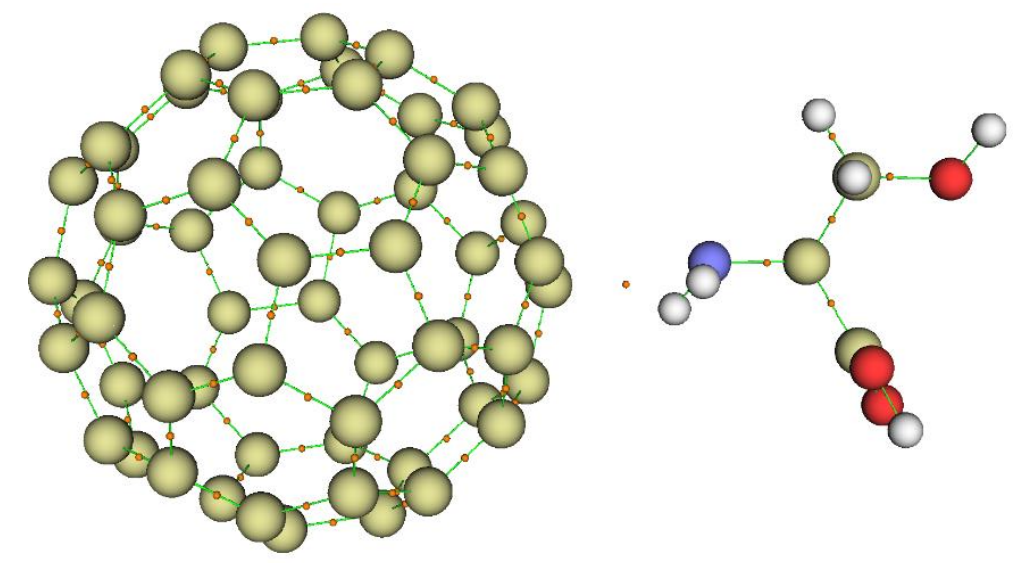

(a)

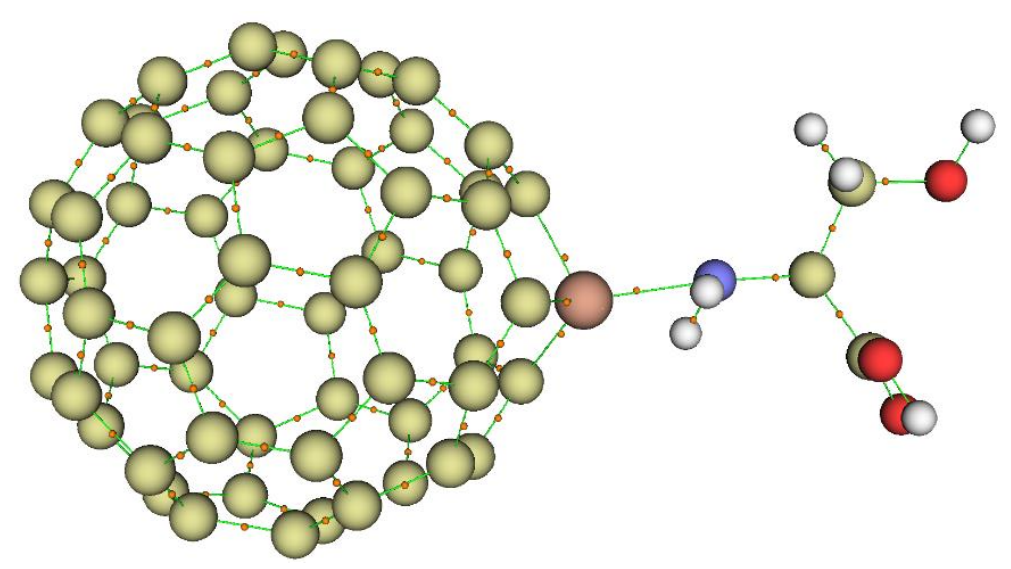

(b)

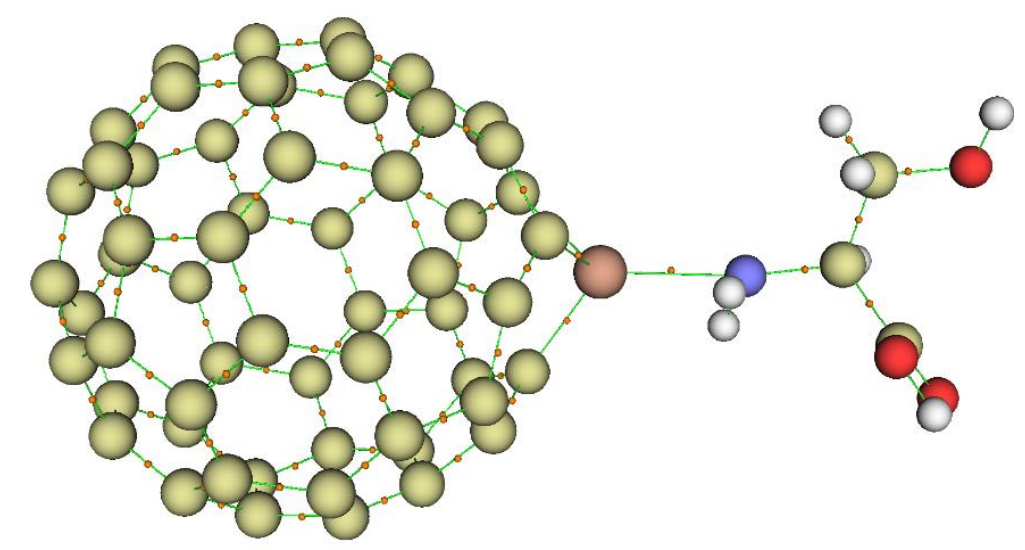

(c)

482 Fig. 6. AIM molecular graphs for (a) Serine/ $\mathrm{C}_{60}$, (b) Serine $/ \mathrm{C}_{59} \mathrm{Si}$, and (c) Serine $/ \mathrm{C}_{59} \mathrm{Ge}$ systems. Orange dots 483 represent the boundary critical points (BCPs). 

are defined; in the $\operatorname{sign} \lambda_{2}(\mathbf{r}) \rho(\mathbf{r})>0$ region, repulsion forces are dominant [140,141]. Fig. 7 502 compares the NCI plots for both isolated nanocages and amino acid/nanocages clusters. 503 Repetitive results from previous analyses are also shown in the NCI analysis. That is, in the case 504 of $\mathrm{C}_{59} \mathrm{Si}$ and $\mathrm{C}_{59} \mathrm{Ge}$ adsorbents, the adsorption intensity is stronger than in others. To reference 505

\subsection{NCI analysis}

The results obtained from the previous sections show that the interactions between the amino acid molecule and pure and doped nanocages are non-covalent. Therefore, to verify this, these interactions were examined in terms of NCI analysis to determine the accuracy of the results. NCI analysis uses two functions: (1) $\operatorname{sign} \lambda_{2}(r) \rho(r)$ (product of electron density and the sign of the second Hessian eigenvector) and (2) reduced density gradient (RDG), which is a dimensionless form of a gradient of electron density [140]. The values of these two functions are displayed on a two-dimensional coordinate plane: the $\operatorname{sign} \lambda_{2}(r) \rho(r)$ is placed on the $\mathrm{x}$-axis, and the RDGs are displayed on the vertical axis. The following equation is used to obtain the RDG values $[140,141]$ :

$$
R D G=\frac{1}{2\left(3 \pi^{2}\right)^{\frac{1}{3}}} \frac{|\overline{\Delta \rho}(\mathbf{r})|}{\overline{\rho(\mathbf{r})^{\frac{4}{3}}}}
$$

Depending on the position of the second function in the diagram, three areas are created, indicating the type of interactions. In the $\operatorname{sign} \lambda_{2}(\mathbf{r}) \rho(\mathbf{r})<0$ region, strong non-covalent interactions are found; in the $\operatorname{sign} \lambda_{2}(\mathbf{r}) \rho(\mathbf{r}) \approx 0$ region, relatively weak van der Waals interactions this, $\operatorname{sign} \lambda_{2}(r) \rho(r) \approx 0$ and $R D G \approx 0.5$ should be considered. 


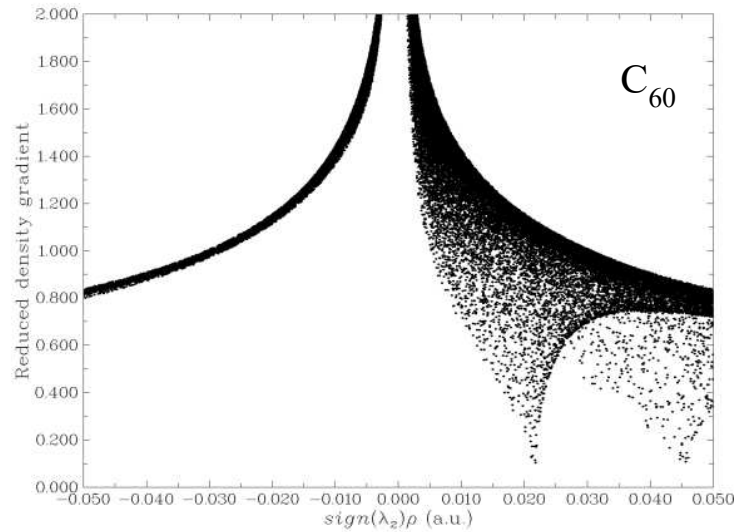

(a)
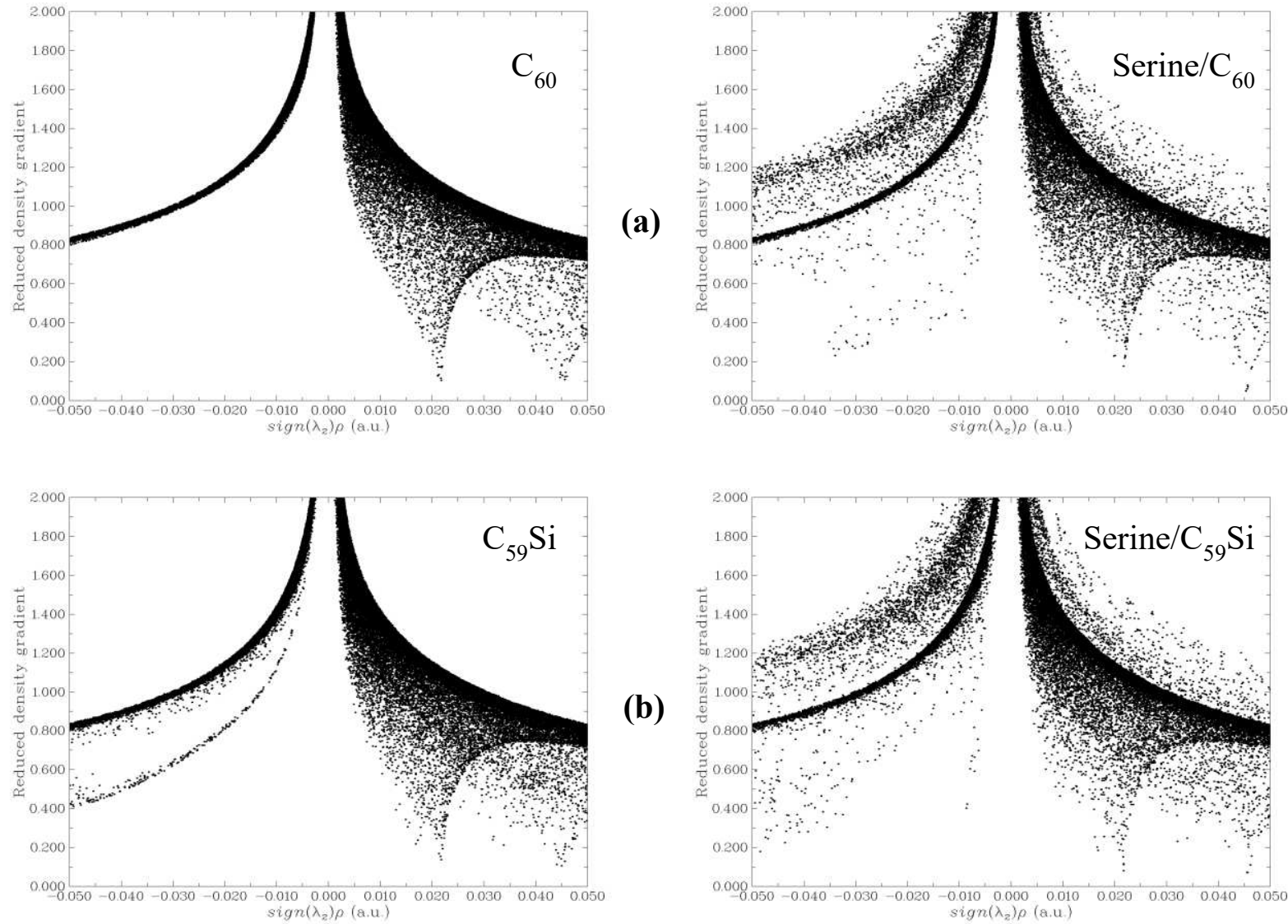

(b)
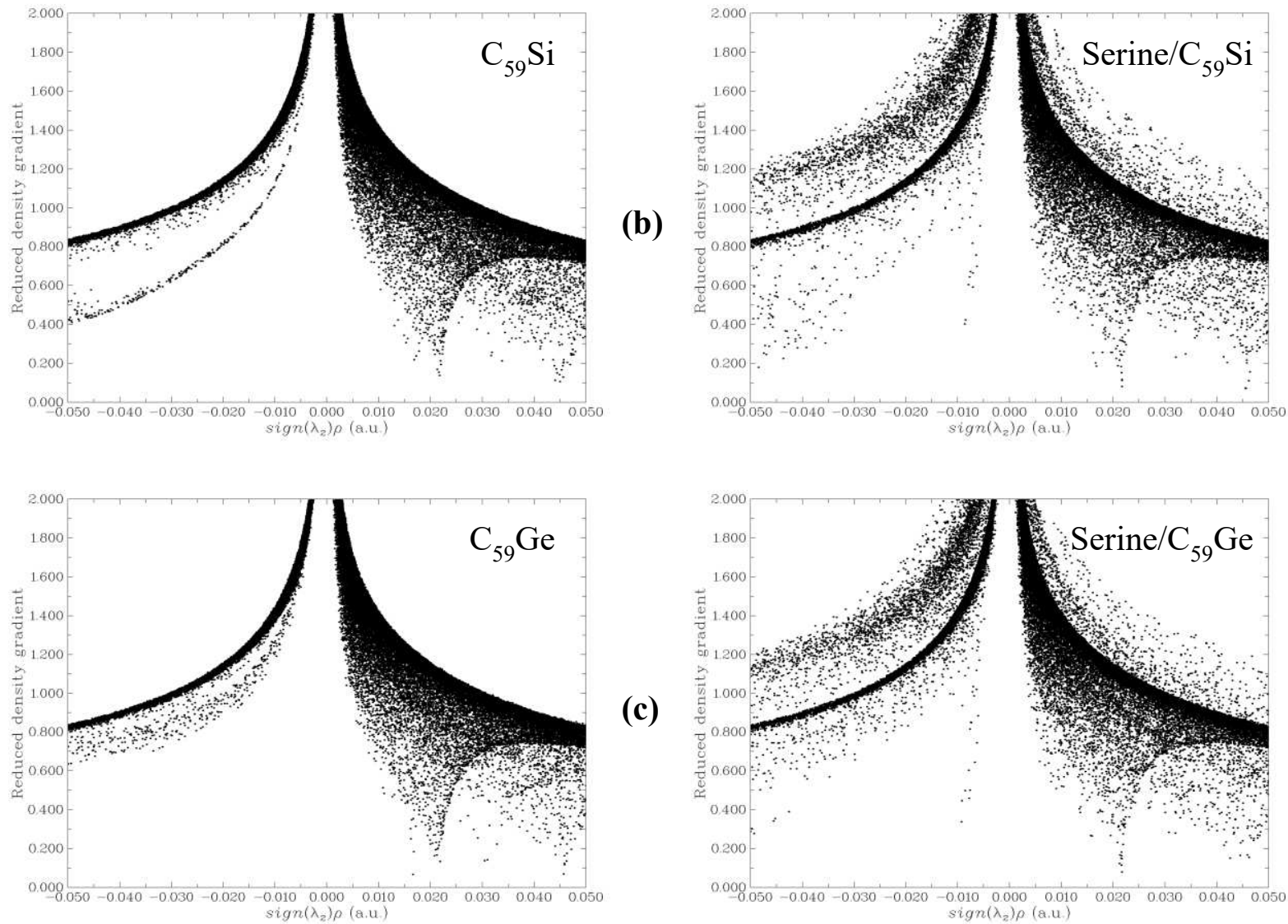

Fig. 7. Plots for the reduced density gradient (RDG) vs. $\operatorname{sign}\left(\lambda_{2}\right) \rho(\mathrm{r})$ values of (a) C60 and Serine/C60, (b) C59Si and Serine/ $\mathrm{C}_{59} \mathrm{Si}$, and (c) $\mathrm{C}_{59} \mathrm{Ge}$ and Serine/ $\mathrm{C}_{59} \mathrm{Ge}$. The data were obtained from B3LYP-D3 /6-311G (d) level of theory. The left side diagrams are isolated nanocages and the right side diagrams are $\mathrm{BCF} /$ nanosheet clusters. 


0

1

2

\section{Conclusion}

Various wave function analyses were performed to study the intermolecular interactions between the Serine amino acidand and fullerene nanosorbents. The standard model chemistry in this study was B3LYP-D3/6-311G(d), which was implemented for the geometry optimization process and NBO calculations. The PBE0, $\omega$ B97XD, and M06-2X functionals and the 6-311G(d) basis set were also used for geometry optimization. Considering the dispersion in these functionals was a factor that completely changed the results of these calculations. In the optimization process, the spatial orientations of the two monomers relative to each other were the determining factors that led to the finding of the local minima. Spanning the entire potential energy surface for such interactions could not be attained. Therefore, it is important to use an appropriate algorithm to find the local minima. The comparison of the adsorption energy of different clusters showed that the adsorbents $\mathrm{C}_{59} \mathrm{Si}$ and $\mathrm{C}_{59} \mathrm{Ge}$ trapped the amino acid molecule more intensely. The results of QTAIM and NCI analysis identified the intermolecular interactions of the type of strong van der Waals interaction for these nanocages. As the amino acid and the mentioned adsorbents interacted well, these nanomaterials could be used in the design a nanocarrier for Serine molecule.

(1)




\section{Declarations}

$538 *$ Ethics approval and consent to participate

$539 *$ Consent for publication

$540 *$ Availability of data and materials

$541 *$ Competing interests

$542 *$ Funding

All authors agree

All authors agree

Not applicable

543 * Authors' contributions Mohsen Doust Mohammadi: Investigation, Writing - original

544 draft. Hewa Y. Abdullah: Conceptualization, Writing - review \& editing, Resources,

545 Supervision.

$546 *$ Acknowledgements We would like to thank the Solid-State Theory Group at the Physics

547 Department at the Universita' ${ }^{6}$ Degli Studi di Milano-Italy for providing computational

548 facilities.

$549 *$ Authors' information (optional).

550 Please include the sub-sections below of Compliance with Ethical Standards section.

* Disclosure of potential conflicts of interest: The authors declare that they have no known competing financial interests or personal relationships that could have appeared to

554 influence the work reported in this paper.

$555 *$ Research involving Human Participants and/or Animals

556

* Informed consent

Not applicable

All authors agree

557

\section{Reference}

1. Clausius R (1857). Annalen der Physik 176 (3):353-380

560

2. Van der Waals JD (1873) Over de Continuiteit van den Gas-en Vloeistoftoestand, vol 1. Sijthoff,

3. London F (1930). Zeitschrift für Physik 63 (3-4):245-279

562

563

564

4. London F (1937). Transactions of the Faraday Society 33:8b-26

5. Spencer ND, Moore JH (2001) Encyclopedia of chemical physics and physical chemistry: Applications, vol 3. Taylor \& Francis,

565 6. Dykstra CE (1988). Studies in physical and theoretical chemistry (58)

566 7. Elrod MJ, Saykally RJ (1994). Chemical reviews 94 (7):1975-1997

567 8. Stone AJ (1996). Oxford Stone AJ, Alderton M (1985) Distributed multipole analysis-methods and 568 applications Mol Phys 56:1047-1064

569 9. Hayes I, Stone A (1984). Molecular Physics 53 (1):83-105

570

571

10. Jeziorski B, Moszynski R, Szalewicz K (1994). Chemical Reviews 94 (7):1887-1930

572 12. Kreek H, Meath WJ (1969). The Journal of Chemical Physics 50 (6):2289-2302

573 13. Knowles PJ, Meath WJ (1986). Molecular Physics 59 (5):965-984

574 14. Wheatley RJ, Meath WJ (1994). Chemical physics 179 (3):341-364

575 15. Van Duijneveldt FB, van Duijneveldt-van de Rijdt JG, van Lenthe JH (1994). Chemical Reviews 94

576 (7):1873-1885

577 16. lijima S (1991). nature 354 (6348):56-58

578 17. lijima S, Ichihashi T (1993). nature 363 (6430):603-605

579 18. Geim AK, Novoselov KS (2010) The rise of graphene. In: Nanoscience and technology: a collection of

580 reviews from nature journals. World Scientific, pp 11-19 
19. Novoselov KS, Geim AK, Morozov SV, Jiang D, Katsnelson MI, Grigorieva I, Dubonos S, Firsov, AA (2005). nature 438 (7065):197-200

20. Novoselov KS, Geim AK, Morozov SV, Jiang D, Zhang Y, Dubonos SV, Grigorieva IV, Firsov AA (2004). science 306 (5696):666-669

21. Novoselov KS, Jiang D, Schedin F, Booth T, Khotkevich V, Morozov S, Geim AK (2005). Proceedings of the National Academy of Sciences 102 (30):10451-10453

22. Guerra V, Wan C, McNally T (2019). Progress in Materials Science 100:170-186

23. Li J-I, Yin J-h, Ji T, Feng Y, Liu Y-y, Zhao H, Li Y-p, Zhu C-c, Yue D, Su B (2019). Materials Letters 234:7478

24. Yang X, Guo Y, Han Y, Li Y, Ma T, Chen M, Kong J, Zhu J, Gu J (2019). Composites Part B: Engineering $175: 107070$

25. Zhi C, Bando Y, Tang C, Kuwahara H, Golberg D (2009). Advanced Materials 21 (28):2889-2893

26. Watanabe K, Taniguchi T, Kanda H (2004). Nature materials 3 (6):404-409

27. Lin Y, Connell JW (2012). Nanoscale 4 (22):6908-6939

28. Doust Mohammadi M, Abdullah HY (2020). ChemistrySelect 5 (39):12115-12124

29. Doust Mohammadi M, Abdullah HY (2020). Canadian Journal of Chemistry (999):1-12

30. Mohammadi MD, Abdullah HY (2020). Journal of Molecular Modeling 26 (10):1-15

31. Mohammadi MD, Abdullah HY (2020). Theoretical Chemistry Accounts 139 (10):1-17

32. Mohammadi MD, Abdullah HY (2020). Structural Chemistry:1-14

33. Mohammadi MD, Abdullah HY (2020). Computational and Theoretical Chemistry:113047

34. Mohammadi MD, Salih IH, Abdullah HY (2020). Journal of Theoretical and Computational Chemistry

35. Mohammadi MD, Salih IH, Abdullah HY (2020). Molecular Simulation:1-12

36. Nemati-Kande E, Abbasi M, Mohammadi MD (2020). Journal of Molecular Structure 1199:126962

37. Mohammadi MD, Abdullah HY, Bhowmick S, Biskos G (2021). Computational and Theoretical Chemistry 1198:113168

38. Mohammadi MD, Abdullah HY, Bhowmick S, Biskos G (2021). Canadian Journal of Chemistry 0 (0):19. doi:10.1139/cjc-2020-0473

39. Mohammadi MD, Abdullah HY (2021). Solid State Communications: 114440

40. Peer D, Karp JM, Hong S, Farokhzad OC, Margalit R, Langer R (2020). Nano-Enabled Medical Applications:61-91

41. Rad AS, Aghaei SM (2018). Current Applied Physics 18 (2):133-140

42. Torchilin VP (2012). Advanced drug delivery reviews 64:302-315

43. Schlegel HB (1982). Journal of computational chemistry 3 (2):214-218

44. Perdew JP, Ernzerhof M, Burke K (1996). The Journal of chemical physics 105 (22):9982-9985

45. Adamo C, Barone V (1999). The Journal of chemical physics 110 (13):6158-6170

46. Perdew JP, Burke K, Ernzerhof M (1996). Physical review letters 77 (18):3865

47. Zhao Y, Truhlar DG (2008). Theoretical chemistry accounts 120 (1):215-241

48. Zhao Y, Truhlar DG (2006). The Journal of Physical Chemistry A 110 (49):13126-13130

49. Chai J-D, Head-Gordon M (2008). Physical Chemistry Chemical Physics 10 (44):6615-6620

50. Grimme $S$ (2006). Journal of computational chemistry 27 (15):1787-1799

51. Grimme S, Antony J, Ehrlich S, Krieg H (2010). The Journal of chemical physics 132 (15):154104

52. Grimme S, Ehrlich S, Goerigk L (2011). Journal of computational chemistry 32 (7):1456-1465

53. Frisch MJ, Trucks GW, Schlegel HB, Scuseria GE, Robb MA, Cheeseman JR, Scalmani G, Barone V, Petersson GA, Nakatsuji H, Li X, Caricato M, Marenich AV, Bloino J, Janesko BG, Gomperts R, Mennucci $B$, Hratchian HP, Ortiz JV, Izmaylov AF, Sonnenberg JL, Williams, Ding F, Lipparini F, Egidi F, Goings J, Peng B, Petrone A, Henderson T, Ranasinghe D, Zakrzewski VG, Gao J, Rega N, Zheng G, Liang W, Hada M, Ehara M, Toyota K, Fukuda R, Hasegawa J, Ishida M, Nakajima T, Honda Y, Kitao O, Nakai H, Vreven T, Throssell K, Montgomery Jr. JA, Peralta JE, Ogliaro F, Bearpark MJ, Heyd JJ, Brothers EN, Kudin KN, 
Staroverov VN, Keith TA, Kobayashi R, Normand J, Raghavachari K, Rendell AP, Burant JC, lyengar SS, Tomasi J, Cossi M, Millam JM, Klene M, Adamo C, Cammi R, Ochterski JW, Martin RL, Morokuma K, Farkas O, Foresman JB, Fox DJ (2016) Gaussian 16 Rev. C.01. Wallingford, CT

54. Binning Jr R, Curtiss L (1990). Journal of Computational Chemistry 11 (10):1206-1216

55. Curtiss LA, McGrath MP, Blaudeau JP, Davis NE, Binning Jr RC, Radom L (1995). The Journal of Chemical Physics 103 (14):6104-6113

56. Frisch MJ, Pople JA, Binkley JS (1984). The Journal of chemical physics 80 (7):3265-3269

57. Hay PJ (1977). The Journal of Chemical Physics 66 (10):4377-4384

58. J.-P. Blaudeau MPM, L. A. Curtiss, and L. Radom (1997). J Chem Phys 107:5016-5021

59. K. Raghavachari JSB, R. Seeger, and J. A. Pople (1980). J Chem Phys 72 650-654

60. McGrath MP, Radom L (1991). The Journal of Chemical Physics 94 (1):511-516

61. Raghavachari K, Trucks GW (1989). The Journal of chemical physics 91 (2):1062-1065

62. Russo TV, Martin RL, Hay PJ (1994). The Journal of chemical physics 101 (9):7729-7737

63. Goerigk L, Grimme S (2011). Physical Chemistry Chemical Physics 13 (14):6670-6688

64. Mardirossian N, Head-Gordon M (2017). Molecular Physics 115 (19):2315-2372

65. Brakestad A, Jensen SR, Wind P, D'Alessandro M, Genovese L, Hopmann KH, Frediani L (2020). Journal of chemical theory and computation 16 (8):4874-4882

66. Mitra H, Roy TK (2020). The Journal of Physical Chemistry A 124 (44):9203-9221

67. Goerigk L, Hansen A, Bauer C, Ehrlich S, Najibi A, Grimme S (2017). Physical Chemistry Chemical Physics 19 (48):32184-32215

68. Dennington R, Keith TA, Millam JM (2016). Semichem Inc Shawnee Mission KS

69. Andrienko G (2010) Chemcraft. Graphical Software for Visualization of Quantum Chemistry Computations. https://www.chemcraftprog.com,

70. Foster aJ, Weinhold F (1980). Journal of the American Chemical Society 102 (24):7211-7218

71. Reed AE, Weinhold F (1983). The Journal of chemical physics 78 (6):4066-4073

72. Carpenter J, Weinhold F (1988). Journal of Molecular Structure: THEOCHEM 169:41-62

73. Lu T, Chen F (2012). Journal of computational chemistry 33 (5):580-592

74. O'boyle NM, Tenderholt AL, Langner KM (2008). Journal of computational chemistry 29 (5):839-845

75. Mayer I, Valiron P (1998). The Journal of chemical physics 109 (9):3360-3373

76. Boys SF, Bernardi F (1970). Molecular Physics 19 (4):553-566

77. Alkorta I, Trujillo C, Elguero J, Solimannejad M (2011). Computational and Theoretical Chemistry 967 (1):147-151

78. Thomas LH The calculation of atomic fields. In: Mathematical proceedings of the Cambridge philosophical society, 1927. vol 5. Cambridge University Press, pp 542-548

79. Fermi E (1927). Rend Accad Naz Lincei 6 (602-607):5

80. Dirac PA Note on exchange phenomena in the Thomas atom. In: Mathematical proceedings of the Cambridge philosophical society, 1930. vol 3. Cambridge University Press, pp 376-385

81. Slater JC (1951). Physical review 81 (3):385

82. Hohenberg P, Kohn W (1964). Physical review 136 (3B):B864

83. Kohn W, Sham L (1965). Physical review 140 (4A):A1133

84. Becke AD (2014). The Journal of chemical physics 140 (18):18A301

85. Burke K, Wagner LO (2013). International Journal of Quantum Chemistry 113 (2):96-101

86. Becke AD (1988). Physical review A 38 (6):3098

87. Gill PM (1996). Molecular Physics 89 (2):433-445

88. Vosko SH, Wilk L, Nusair M (1980). Canadian Journal of physics 58 (8):1200-1211

89. Perdew JP (1986). Physical Review B 33 (12):8822

90. Lee C, Yang W, Parr RG (1988). Physical review B 37 (2):785

91. Perdew JP, Zunger A (1981). Physical Review B 23 (10):5048 
722

723

92. Cole LA, Perdew J (1982). Physical Review A 25 (3):1265

93. Perdew JP, Wang Y (1992). Physical review B 45 (23):13244

94. Becke AD (1997). The Journal of chemical physics 107 (20):8554-8560

95. Perdew JP, Chevary JA, Vosko SH, Jackson KA, Pederson MR, Singh DJ, Fiolhais C (1992). Physical review B 46 (11):6671

96. Paier J, Marsman M, Kresse G (2007). The Journal of chemical physics 127 (2):024103

97. Yanai T, Tew DP, Handy NC (2004). Chemical physics letters 393 (1-3):51-57

98. Leininger T, Stoll H, Werner H-J, Savin A (1997). Chemical physics letters 275 (3-4):151-160

99. Bhatta RS, Pellicane G, Tsige M (2015). Computational and Theoretical Chemistry 1070:14-20

100. Sekar N, Katariya S, Rhyman L, Alswaidan IA, Ramasami P (2019). Journal of fluorescence 29 (1):241-253

101. Tao J, Perdew JP, Staroverov VN, Scuseria GE (2003). Physical Review Letters 91 (14):146401

102. PubChem database, https://pubchem.ncbi.nlm.nih.gov/, 2021.

103. Kohl D (1990). Sensors and Actuators B: Chemical 1 (1-6):158-165

104. Foresman JB, Frisch A (1996).

105. MOHAMMADI MD, ABDULLAH HY, BISKOS G, BHOWMICK S (2021). Bulletin of Materials Science 44 106. Mohammadi MD, Abdullah HY, Suvitha A (2021). Iranian Journal of Science and Technology, Transactions A: Science. doi:10.1007/s40995-021-01117-0

107. Geerlings P, De Proft F, Langenaeker W (2003). Chemical reviews 103 (5):1793-1874

108. Islam N, Kaya S (2018) Conceptual density functional theory and its application in the chemical domain. CRC Press, 109. Chermette $H$ (1999). Journal of computational chemistry 20 (1):129-154

110. Pearson RG (2005). Journal of Chemical Sciences 117 (5):369-377

111. Ayers PW, Anderson JS, Bartolotti LJ (2005). International Journal of Quantum Chemistry 101 (5):520-534

112. Bultinck P, Cardenas C, Fuentealba P, Johnson PA, Ayers PW (2013). Journal of chemical theory and computation 9 (11):4779-4788

113. Bultinck P, Cardenas C, Fuentealba P, Johnson PA, Ayers PW (2014). Journal of chemical theory and computation 10 (1):202-210

114. Parr RG, Donnelly RA, Levy M, Palke WE (1978). The Journal of Chemical Physics 68 (8):3801-3807

115. Parr RG, Pearson RG (1983). Journal of the American chemical society 105 (26):7512-7516

116. Parr RG, Yang W (1984). Journal of the American Chemical Society 106 (14):4049-4050

117. Yang W, Parr RG, Pucci R (1984). The Journal of Chemical Physics 81 (6):2862-2863

118. Morell C, Grand A, Toro-Labbe A (2005). The Journal of Physical Chemistry A 109 (1):205-212

119. Levy M (1982). Physical Review A 26 (3):1200

120. Parr RG, Szentpály Lv, Liu S (1999). Journal of the American Chemical Society 121 (9):1922-1924

121. Bredas J-L (2014). Materials Horizons 1 (1):17-19

122. Koopmans $T$ (1934). physica 1 (1-6):104-113

123. Janak J (1978). Physical Review B 18 (12):7165

124. Schmidt MW, Hull EA, Windus TL (2015). The Journal of Physical Chemistry A 119 (41):10408-10427

125. Mulliken RS (1932). Physical Review 41 (1):49

126. Löwdin P-O (1955). Physical Review 97 (6):1474

127. Coulson CA (1939). Proceedings of the Royal Society of London Series A Mathematical and Physical Sciences 169 (938):413-428

128. Mulliken RS (1955). The Journal of Chemical Physics 23 (10):1833-1840

129. Mayer I (1983). Chemical Physics Letters 97 (3):270-274

130. Mayer I (2012). Chemical Physics Letters 544:83-86 
724 131. Bridgeman AJ, Cavigliasso G, Ireland LR, Rothery J (2001). Journal of the Chemical Society, Dalton 725 Transactions (14):2095-2108

726 132. Wiberg KB (1968). Tetrahedron 24 (3):1083-1096

727 133. Sizova OV, Skripnikov LV, Sokolov AY (2008). Journal of Molecular Structure: THEOCHEM 870 (1728 3):1-9

729 134. Bader RF (1985). Accounts of Chemical Research 18 (1):9-15

730 135. Bader R (1990) A Quantum Theory, Clarendon. Oxford,

731 136. Bader RFW, Popelier PLA, Keith TA (1994). Angewandte Chemie International Edition in English 33 732 (6):620-631

733 137. Matta CF (2006) Hydrogen-hydrogen bonding: the non-electrostatic limit of closed-shell interaction 734 between two hydro. In: Hydrogen Bonding-New Insights. Springer, pp 337-375

735 138. Grabowski SJ (2012). The Journal of Physical Chemistry A 116 (7):1838-1845

736 139. Bohórquez HJ, Boyd RJ, Matta CF (2011). The Journal of Physical Chemistry A 115 (45):12991-12997

737 140. Johnson ER, Keinan S, Mori-Sánchez P, Contreras-García J, Cohen AJ, Yang W (2010). Journal of the 738 American Chemical Society 132 (18):6498-6506

739 141. Contreras-García J, Johnson ER, Keinan S, Chaudret R, Piquemal J-P, Beratan DN, Yang W (2011).

740 Journal of chemical theory and computation 7 (3):625-632

741 